\title{
Human Resource Management Models to Support Emotional Labor during Emergencies in Jordan
}

\author{
Submitted 10/04/20, $1^{\text {st }}$ revision 14/05/20, $2^{\text {nd }}$ revision 11/07/20, accepted 15/08/20
}

\author{
Ahmad Ali Almohtaseb ${ }^{1}$, Hisham A. Kareem Shaheen ${ }^{2}$, Amer Saadi Kallel \\ Shakkour ${ }^{3}$, Lama Ismail Mohammad Ahmad ${ }^{4}$, Ahmad Abdullah abu Jray ${ }^{5}$
}

\begin{abstract}
:
Purpose: This study was conducted to establish the new model of human resource management in order to support and manage the emotional labor during emergencies in Jordanian public hospitals.

Design/Methodology/Approach: The study performs along with burnout and intention to leave, where, high-performance work system (HPWS) acts as a mediator. In addition, the study uses correlational and cross-sectional surveys. The survey questionnaire was distributed among the nurses and midwives of a public hospital in Jordan.

Findings: The study concluded that the emotional labor (EL) is positively connected with intention to leave (ITL) and burnout. The factor of HPWS negatively moderates EL and burnout. The study concluded that designing effective Human Resource practices can help in lessening the burnout which is linked with EL. This can influence the organizations to cope with the ITL among nurses and midwives.

Practical Implications: The proposed model will prove to be the effort made in the way of HRM policies and behavior regarding emotional labor throughout the emergency situation. The study will be useful for firms in designing their policies and strategies that support emotional labor in emergencies.

Originality/Value: The new model of human resource management which has been established in this study to support and manage emotional labor in the presence of a highperformance work system that acts as a mediator.
\end{abstract}

Keywords: Emotional labor, high-performance work system, burnout, intention to leave.

JEL codes: M50, M54, O15.

Paper type: Research article.

\footnotetext{
${ }^{1}$ Assistant Professor, Al Hussein Bin Talal University, Business Department, Ma'anJordan, Muhtaseb_ma@yahoo.com

${ }^{2}$ Amman Training College, UNRWA, Business School, Amman - Jordan

Hisham_shaheen2003@yahoo.com

${ }^{3}$ Assistant Professor, Al Hussein Bin Talal University, Accounting and Finance Department,

Ma'an-Jordan Amer_shkor@yahoo.com

${ }^{4}$ Amman Training College, UNRWA, Business School, Amman - Jordan

Lomi2006@yahoo.com

${ }^{5}$ Research scholar, a.aljery@ahu.edu.jo
} 


\section{Introduction}

During the recent times, the literature related to organizational behavior recognizes the impact of emotional regulations in offering the explanation referring to jobrelated behavior in workers, specifically in the job sector. The health professionals, mainly discussing to nurses and midwives, their emotional regulation (their aptitude to hold on to their emotional situation creates a direct impact on their jobs (Lartey, Amponsah-Tawiah, and Osafo, 2019). The factor of emotional labor is especially significant for nursing professionals since the nurses and midwives are many times "emotional jugglers" who are needed to express their emotion just according to what their colleagues and patients expect them to show.

It is often observed that the emotional labors may face adverse health consequences due to their emotionally demanding nature of the job and it can also be among the significant predictors of burnout (Bartram et al., 2012). Following Nantsupawat et al. (2017), in emotionally demanding jobs such as nursing and midwives, the factor of burnout has been highlighted as positively linked with the intention to leave. In addition, it is adversely linked to the quality of the patient's care (Van Bogaert et al., 2014). Designing effective human resource practices is important for retaining nurses and ensuring the quality of health care (Lartey, Amponsah-Tawiah, and Osafo, 2019). The interest has been found in the part played by a high-performance work system (HPWS) in inspiring the behavior and attitude of healthcare profession (Bartram et al., 2012).

HPWS is known to be "a set of the individual but linked human resource practices that select, develop, recruit, and retain the staffs" (Huang et al., 2016). It has been claimed that HPWS influences the worker's job performance and behavior through information sharing, decentralized decision-making, extensive training, selective recruitment, and teamwork (Jensen, Patel, and Messersmith, 2013). Emotional labor (EL) particularly means "the struggle that is made to control the expression of emergency workers' emotions to come across the anticipations of employers or customers". These anticipations are rounded on display rules or customs that are a concern to suitable emotional expressions for particular conditions (Delgado et al., 2017). The organizational workers that are mainly exposed to emotional labor are those who are more in contact with customers in an emotional situation such as nurses and midwives.

Following Bakker, Demerouti, and Sanz-Vergel (2014), the factor of turnout is a kind of psychological syndrome that shows the missing concern with the staff with whom a person is working. It is mainly linked with the staff that is associated with healthcare professions. HPWS helps the workers in achieving their organizational objectives as well as working on organizational and individual efficiency (Jensen, Patel, and Messersmith, 2013). This study will observe the relationship between IL, HPWS, ITL, and burnout among emergency workers such as nurses and midwives by using Job demand-resources model (JD-R) (Biron, and Van Veldhoven, 2012). 
The occupational distress, emotional labor, and burnout strongly derive the nurse and midwives towards shifting their career (Freitas et al., 2014). Following the dissonance model describing the emotional labor, the factor of burnout can be a helpful tool in describing the link between intention to leave and emotional labor. Holding a competing intention might give rise to emotional exhaustion and which can consequently inspire withdrawal behavior such as the intention to leave or career shift (Alrawadieh et al., 2019).

Increasing evidence from studies in human resource management shows that human resource management is not an advocate for employees, especially given the increasing demand for services, organizational delays, and the large amount of emotional work required to provide services. People have to align. Different types of first responders engage in emotional work including paramedics, nurses, doctors, social workers, police, and paramedics. The human resources administration has not yet addressed the emotional loss they are experiencing (Pandey, 2018). The lack of literature on human resource management revolves primarily around understanding the relationships between human resource management roles (Tofighi et al., 2015). Scholars need to take an effective step into generating the literature that can undertake the issues of emotional labor in emergency situations. In addition, the department of HRM must consider work on these issues as well to promote the prosperity and well-being of workers to minimize the turnover ratio and burnout within the organization. There is no study that is conducted on a bigger platform that addresses the relationship between HPWs and emotional labor for nurses. This particular gap will be addressed in the study.

The purpose of this article is to examine the role of human resource management in supporting the well-being of rescuers who use HPWS as a mediating variable to provide basic services. This article also integrates the role of human resource management in the continuity of social benefits and employee performance. In addition, this research paper develops and analyzes human resource management models that conceptualize emotional work based on the role of emotions in promoting employee well-being and the performance of first responders to a workforce. The research questions to be addressed are:

1. What is the impact of emotional labor on employee's burnout?

2. What is the significance of emotional labor in health professional's intention to leave?

3. Identify the mediating impact of a high-performance work system.

\section{Literature Review}

\subsection{Job Demand-Resources Theory}

The job demand-resources model which is abbreviated as the JD-R model is a theory that inspires the functioning of worker's well-being. This model is widely used by 
supervisors and executives to promote employee's involvement. The suggestions that are made by the work-stress model states that the level of stress is generated in employees through inequality between job demand and the resources that are available with the employee to overcome those demands (Bakker, and Demerouti, 2014). To address the gap of the study, JD-R theory has been stated to study the relationship between emotional labor, HPWS, intention to leave (ITL), and burnout among health care professionals in organizations such as nurses and midwives. This theory can be used for providing some major insights into the procedure of how emotional labor could be coped efficiently (Bartram et al., 2012). The scholars claim that helpful working conditions assisted by a high-performance work system, which can consist of confirming employees reach satisfaction with work-life balance, are significant resources in decreasing the demands of the work.

Resources like these also help as a barrier to perceived high levels of workload and job demands. HIWPs as a result, possibly permit staff to stock up their resources (Macky and Boxall, 2008). This locates the policies and practices of human resource management at the center of policies to reduce the undesirable influence that high perceived workload has on worker's well-being. These strategies and practices are possibly to deliver the chance to confirm the improved satisfaction of workers with the equilibrium among work and life and as a result, diminish the worker's intention to leave the job (Bakker, Demerouti, and Sanz-Vergel, 2014).

\subsection{Dissonance Model}

Cognitive dissonance discusses a state linking the conflicting outlooks, philosophies, or actions. This generates a sense of psychological discomfort that leads to a change in one of the outlooks, philosophies, or activities to decrease the distress and reestablish the equilibrium (Antoniou, Doukas, and Subrahmanyam, 2013). The emotional labor theory pursues to comprehend by what means the individuals manage with the occurrence of conflicts among their internal natures and external actualities, particularly dissonance among performance and principles (Santos, Mustafa, and Gwi, 2015). As being the major internal service providers, the job of human resource professional's stresses widespread interpersonal communications with others. The suppression of real negative feelings in the service communication also specifies an adverse communication and, consecutively, needs determination, demanding emotional resources (van der Togt and Rasmussen, 2017). The suffering emotional dissonance could be unavoidable by means of the high-stress work setting that typically includes extended functioning hours, shifting work schedules, heavy loads, and challenging customers (Zhao, Qu, and Ghiselli, 2011).

\subsection{Empirical Studies}

\subsubsection{Emotional labor}

It has been observed by early researches that emotional labor is closely associated with burnout and it further lead employees towards intention to leave due to their 
high demanding jobs (Bartram et al., 2012). The influence of emotional labor upon the individual differs just conferring to the rate of recurrence, concentration, diversity, and period of the display of the essential emotions and the degree of emotional dissonance among the emotions that are felt and the emotions that are expected (Delgado et al., 2017). Healthcare professionals are connected to the type of profession that is high in emotional labor and as far as OECD countries are concerned, they have a higher turnover rate as compare to any other occupation (Brunetto et al., 2014). The nurses and midwives implement emotional labor since nurses are held accountable for playing their part to human relationships and the sentiments that they are surrounded with, that thoughtfulness and coping with feelings is a nursing skill that is rated on the top and that consideration, spotting and transmitting the sentiment are essential to an occupation that needs compassion within relationships (Smith, Profetto-McGrath, and Cummings, 2009).

In addition, the factor of emotional labor is different by means of a concept from emotional intelligence. EI means having an ability while EL refers to acting on that ability. The EL is highlighted as the core aspect of HR practices. The employees expressed their emotions on a regular basis in a suitable manner with their coworkers, managers, and employees. It is widely assumed that expressions must necessarily be expressed in a pre-determined manner. The type of policies that HR needs to implement depends on multiple contextual and individual factors (O'Brien, and Linehan, 2016).

\subsubsection{High-performance work systems}

The factor of high-performance work system (HPWS) describes a collection of consistent practices of HRM that is mainly centered on flexible job tasks, demanding and selective recruitment, widespread training and development programs, evolving and merit-based appraisal, competitive reward system, and wide-ranging benefits. The key purpose of the HPWS factor is to increase the satisfaction of the employee to the organization and make him own the organization (Andersén and Andersén, 2019). Following the scholars Kloutsiniotis and Mihail (2019), employee autonomy is referred to as one of the key practices of HR that form the HPWS construct. In must be made clear that HPWS is not as effective as it seems like the intense implementation of it could perhaps lead to bigger job demands and eventually to burnout and work intensification (Kroon, van de Voorde, and van Veldhoven, 2009).

According to Karimi et al. (2014), developing the HRM functions such as training and development and performance management as well as the characteristics of high-performance work systems (HPWS) like quality work, transformational leadership, semi-autonomous work teams, and employee participation might propose significant strategies to back and connect the EI of nurses. The practices of human resource management and HPWS to advance and connect the EI of nurses and midwives with the purpose of refining the well-being of nurses, quality of patient care as well as decreasing turnover rates is in its early stages. 


\subsubsection{Burnout}

Though the emotional labor has turned to be one of the key job demands in the competing service industry of today's times, it has an impact on the worker's burnout and emotional exhaustion (Geng et al., 2018). The numerous mental and physical stresses counting burnout, frustration, emotional exhaustion, and uneasiness are recognized as the possible outcomes of emotional dissonance (Alrawadieh et al., 2019). In addition, the previous researches stated that the workers in HPWS-oriented companies are more exposed to burnouts and find it difficult to create an equilibrium with work-life-balance. There is a high turnover ratio among nurses and midwives due to poor execution of human resource practices and it is causing high work stress, burnout as well as an increased turnover ratio. The job of nurses is dominantly connected to high rates of burnout (Karimi et al., 2014).

Following the current literature, the HPWS is capable enough to play an operational part in improving the impacts of emotional labor over burnout in nurses (Bartram et al., 2012). The factor of burnout is a mental syndrome that effects long-lasting, highstress levels at a job. The long-lasting high-job demands derive to emotional exhaustion as being the stress response of an individual, that fallouts in the emotional departure from the job and particularly minor feelings of personal achievement or a feeling capable to do the job (Kroon et al., 2012).

\subsubsection{Intention to leave}

The high burnout ratio in nurses and midwives is connected with a decline within the quality of patient care and it can either directly or incidentally worsen the nurses' intention to leave. The factor of burnout is directly linked to the intention to leave in emergency workers specifically the healthcare workers (Cheng et al., 2013). According to the researcher, to decrease the actual rate of turnover, it is significant to identify the factors that motivate workers and assist in decreasing their intention to leave the firm. The component of high-performance work system can encourage in lowering the intention to leave the organization (García-Chas, Neira-Fontela, and Castro-Casal, 2014). Several pieces of research have claimed a significant association among the emotional labor and intention to leave (Karimi et al., 2014).

Moreover, according to some researchers, there is a negative association between HPWS, burnout, and intention to leave. HPWs increase productivity and on the other hand, reduces the employee's intention to leave. The factor of HPWS offers employees with recognitions, rewards, benefits, work-life balance, prestige, growth as well as fairness at the workplace (Kloutsiniotis and Mihail, 2017). In addition, the engaged employees are more likely to own their organization instead of looking forward to leaving the organization as engagement has a negative association with turnover intention (Jeung, Kim, and Chang, 2018). Intention to leave the organization is mostly practiced when the employees have high demanding jobs and are connected with providing services. Employees who are engaged with the services in organizations are more exposed to emotional labor as they are acting as emergency workers in handling customers and other emergency conditions in the 
organization (García-Chas, Neira-Fontela, and Castro-Casal, 2013). Figure 1 presents the conceptual model of this study.

Figure 1. The Conceptual model

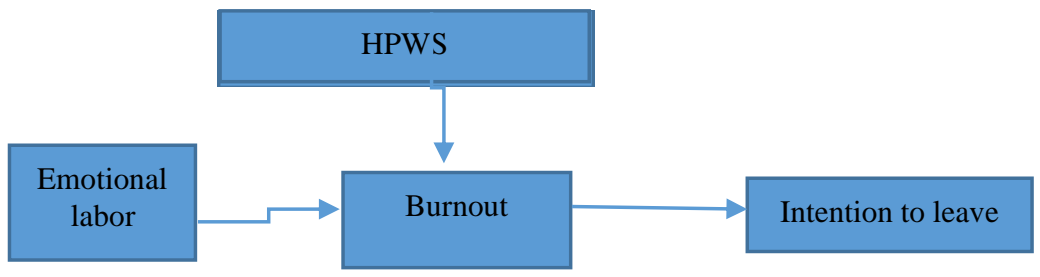

HPWS: high-performance work systems

EL: emotional labor

ITL: intention to leave

Hypothesis

H1: The emotional labor has positive relationship with ITL

H2: Burnout works as a mediator between EL and ITL

H3: HPWS moderated the connection between EL and burnout

Source: Own.

\section{Research Methodology}

For this particular study to propose a conceptual model, a correlational and crosssectional survey was directed in the months of May and June of the present year. The number of respondents that actively participate in the study were 183 nurses and midwives working in a public hospital. The mediator and moderator were tested through Baron and Kenny test and hierarchical regression respectively.

The target population for the study consist of 455 registered health professionals (particularly nurses, nurses' assistants, and midwives). These nurses are from the public hospital in Jordan which is known for its high efficiency and providing highquality care. The respondents of the study contributed voluntarily by filling out the survey questionnaire that was given to them along with their salary slips. A total of 205 completed survey questionnaires were collected out of which, 183 were approved and the rest were left due to missing values.

The study got approval from the HR department of the hospital as well as from the research department of the university. It was made sure that none of the hospital's information will be used for any other purpose rather than drawing out the results for the research. The data analysis is presented in Table 1 and correlation and Cronbach alpha's in Table 2. The entire analysis of the study is done by using the figures of PASW. The first hypothesis is tested through "Pearson's correlational analysis". Moreover, the second hypothesis is examined to know the effect of mediation through Baron and Kenny's method and lastly, the 3rd hypothesis was tested for interaction effects through the Saunders method. In addition, the data was gathered 
using a questionnaire Likert-scale tool. The impact of common method variance was checked by means of a single-component test. The principal component analysis helps in assessing HPWS, ITL, burnout, and emotional labor.

Table 1. Data analysis

\begin{tabular}{|c|c|c|c|c|c|}
\hline & Mean (SD) & Median & Minimum & Maximum & Range \\
\hline Age & $43 \cdot 14(10-36)$ & 43 & 22 & 64 & 42 \\
\hline Emotional Labour & $3.44(0.64)$ & $3-43$ & $2 \cdot 0$ & $5 \cdot 0$ & $3 \cdot 0$ \\
\hline HPWS & $3.18(0.71)$ & $3-28$ & $1 \cdot 2$ & $4 \cdot 8$ & $3 \cdot 6$ \\
\hline Employment Security & $2.62(0.98)$ & 3.00 & 10 & $5 \cdot 0$ & $4 \cdot 0$ \\
\hline Selective Hiring & $2.96(0.74)$ & $3-00$ & 10 & $5 \cdot 0$ & $4 \cdot 0$ \\
\hline Extensive Training & $3.06(0.95)$ & $3-25$ & 10 & $5 \cdot 0$ & $4 \cdot 0$ \\
\hline Self-Managed Teams & $3.29(0.82)$ & $3-25$ & 10 & $5 \cdot 0$ & $4 \cdot 0$ \\
\hline Information Sharing & $3 \cdot 34(0 \cdot 81)$ & $3 \cdot 33$ & 10 & $5 \cdot 0$ & $4 \cdot 0$ \\
\hline Transformational Leadership & $3.40(1.01)$ & $3-50$ & 10 & $5 \cdot 0$ & $4 \cdot 0$ \\
\hline High-Quality Work & $3.27(0.75)$ & $3 \cdot 33$ & 10 & $5 \cdot 0$ & $4 \cdot 0$ \\
\hline Burnout & $3.14(0.69)$ & $3 \cdot 13$ & 10 & $4 \cdot 9$ & $3 \cdot 9$ \\
\hline Intention to Leave & $2 \cdot 71(1 \cdot 20)$ & $2 \cdot 67$ & 10 & $5 \cdot 0$ & $4 \cdot 0$ \\
\hline
\end{tabular}

Source: Own study.

Table 2. Correlation and Cronbach alpha's

Table 3 Correlations and Cronbach Alphas'.

\begin{tabular}{|c|c|c|c|c|c|c|c|c|c|c|c|c|c|c|}
\hline & 1 & 2 & 3 & 4 & 5 & 6 & 7 & 8 & 9 & 10 & 11 & 12 & 13 & 14 \\
\hline 1. Age & - & & & & & & & & & & & & & \\
\hline 2. Gender & $0-19^{4}$ & - & & & & & & & & & & & & \\
\hline 3. Education & $-0.21^{\circ}$ & - & - & & & & & & & & & & & \\
\hline 4. Emotional Labour & $-0-06$ & -0.06 & $-0-06$ & 0.77 & & & & & & & & & & \\
\hline 5. Employment Security & $0-10$ & $-0-17^{*}$ & 0.06 & $-0-16^{\circ}$ & $0-73$ & & & & & & & & & \\
\hline 6. Selective Hiring & 0.00 & $-0.19^{4}$ & 0.09 & $-0.15^{4}$ & $0-62^{* 44}$ & 0.86 & & & & & & & & \\
\hline 7. Extensive Training & 0.00 & $-0-17^{*}$ & $0-11$ & $-0.21^{* 0}$ & $0-57^{240}$ & $0.59 * 74$ & 0.93 & & & & & & & \\
\hline 8. Self-Managed Teams & -0.01 & -0.12 & 008 & $-0 \cdot 16^{*}$ & $0-49$ *थ & $0.58^{* 4 *}$ & $0-69^{* 20}$ & $0-85$ & & & & & & \\
\hline 9. Information Sharing & $-0-10$ & $-0-15^{\text {* }}$ & $0-15$ & $-0.20^{* *}$ & $0-55^{*+4}$ & $0.62^{\text {4*4 }}$ & $0-62^{\text {we* }}$ & $0.61^{* * 4}$ & 0.86 & & & & & \\
\hline 10. Transformational Leadership & -0.03 & $-0-13$ & $0-05$ & $-0.15^{\circ}$ & $0-61^{\text {*** }}-3-3$ & $0.64^{* 47}-3-3$ & $0-68 * * 0$ & $0-71^{\text {*4* }}-3-3$ & $0.77+.4$ & 0.95 & & & & \\
\hline 11. High-Quality Work & 0.01 & $-0-11$ & 0.08 & $-0.17^{*}$ & $0-59$ **4 & $0.60^{724}$ & $0.58^{4+4}$ & $0-69 * * 4$ & $0.61^{7+4}$ & $0-66^{*+4}$ & $0-73$ & & & \\
\hline 12. HPWS & -0.02 & $-0-19^{2}$ & $0-11$ & $-0-21^{\text {*a }}$ & $0.72^{\text {e** }}$ & $0.81^{\text {*4* }}$ & $0-86^{* 40}$ & $0-82^{2+4}$ & $0.84^{* 24}$ & $0.89^{20 * 4}$ & $0-77^{\text {e+⿱ }}$ & 0.97 & & \\
\hline 13. Burnout & -0.15 & 0.01 & -0.01 & $0.70^{2+24}$ & $-0-30^{2 * 4}$ & $-0.25^{* * *}$ & $-0-32^{* 2 *}$ & $-0-33^{* * *}$ & $-0.28^{* * *}$ & $-0.29^{207}$ & $-0-31^{\circ * 2}$ & $-35^{* * 4}$ & 0.84 & \\
\hline 14. Intention to Leave & $-0-12$ & $0-16^{*}$ & 0,00 & $0-32^{2 * 4}$ & $-0.55^{* 74}$ & $-0.52^{24 *}$ & $-0.47^{498}$ & $-0-49 * *$ & $-0.46^{* * 4}$ & $-0.52^{* 2 *}$ & $-0-48^{\circ * 4}$ & $-0.59 \times 4 \%$ & $0.45^{204}$ & 0.93 \\
\hline
\end{tabular}

Source: Own study.

The correlation and Cronbach alpha are explained in Table 2. The correlation among the components of HPWS is presented extremely high as anticipated. The discriminant validity among burnout and emotional labor is 0.70 . As far as other instruments are concerned that were used to assess the constructs within hypothesis possess a satisfactory discriminate validity.

\section{Results}

As visible in Table 3 the variable of EL has a positive and significant correlation with ITL $(\mathrm{r}=0.32, \mathrm{p}<0.001)$. This value completely supports the first hypothesis. 
Through using Baron and Kenny's method, the second hypothesis was tested. The results found that 1) the EL significantly forecasts ITL where, $b=0.60, t=4.5$ and $p$ $=0.001$. 2) EL significantly forecasts the burnout $b=0.75, t=13.2$ and $p<0.001 .3$ ) The ITL was reverted on EL $b=0.01, t=0.08$ and $p>0.05$ and burnout $0.78, t=4.8$ and $\mathrm{p}<0.001$. The second hypothesis is evaluated as the burnout mediates the connection between EL and ITL. It was made to confirm through Sobel test that the indirect impact of EL on ITL through burnout is significant with the values of $\mathrm{z}=$ 4.49 and $\mathrm{p}=0.001$.

For testing the second hypothesis, the two-step regression analysis was used. This selected method works by multiplying the IVs and the moderator for generating a product term. For reducing the multi-collinearity, the moderator and standard variables are made uniform prior to generating a product term. Adding a productterm falls in significant growth in R-square concerning the product-term, $b=-0.19, \mathrm{p}$ $=0.001$ and $\mathrm{R} 2=0.04 ; \mathrm{R} 2=0.57 . "$

Figure 2. The connection between EL and HPWS over burnout

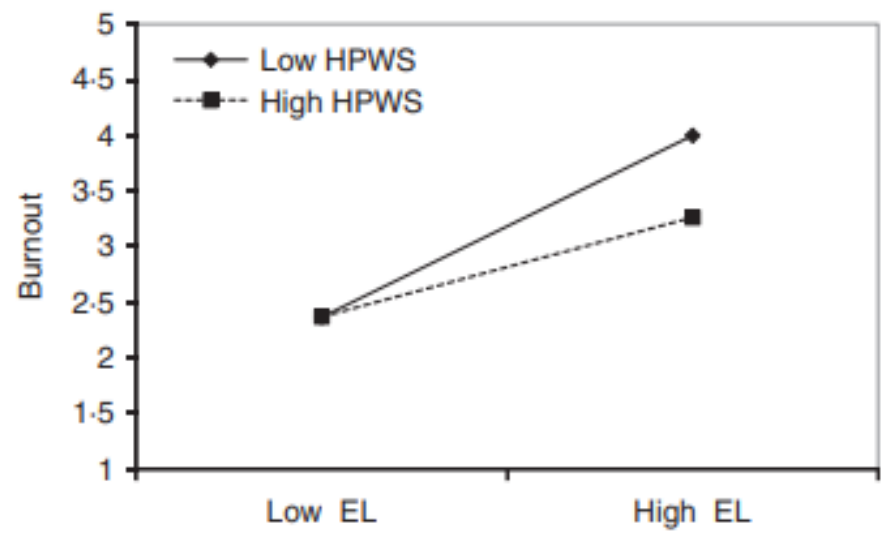

Source: Own study.

As visible in Figure 2, when EL is less, there is no difference found in low and high HPWs groups. On the other hand, when EL is high, the degree of burnout for both of HPWS is high. Whereas, the HPWS appears to make a change only when the EL is high. In addition, the mediator moderation test was done to examine the competing models.

As revealed in Table 3, the EL and HPWS do not possess a significant effect of moderation over ITL but then it has a significant effect of moderation on burnout. The results of Table 3 can be utilized for concluding that burnout has a significant and positive impact on ITL. In addition, the results specify that the variable of HPWS does not just lessen the impact of EL over burnout, however, it also decreases the ITL above the impacts of EL together with the burnout. 
Table 3. Moderator mediation analysis

Table 4 Results for moderated mediation analysis.

\begin{tabular}{|c|c|c|c|c|c|c|c|c|c|}
\hline \multirow[b]{2}{*}{ Criterion } & \multicolumn{3}{|c|}{ Intention to leave } & \multicolumn{3}{|c|}{ Burnout } & \multicolumn{3}{|c|}{ Intention to leave } \\
\hline & $b$ & $t$ & $P$ & $b$ & $t$ & $P$ & $b$ & $t$ & $P$ \\
\hline \multicolumn{10}{|l|}{ Predictors } \\
\hline EL. & 0.24 & 34 & $<0-001$ & 0.43 & $12 \cdot 6$ & $<0-001$ & 0.08 & 0.6 & $0-559$ \\
\hline HPWS & -0.65 & $-9 \cdot 1$ & $<0-001$ & $-0 \cdot 13$ & $-3 \cdot 6$ & $<0-001$ & -0.60 & -8.0 & $<0-001$ \\
\hline EL $\times$ HPWS & -0.03 & $-00-5$ & $0-605$ & $-0 \cdot 13$ & $-4 \cdot 1$ & $<0-001$ & -0.01 & $-0 \cdot 1$ & $0-946$ \\
\hline Burnout & & & & & & & $0 \cdot 28$ & $2 \cdot 1$ & $0-039$ \\
\hline Burnout $\times$ HPWS & & & & & & & 0.04 & $0 \cdot 3$ & $0-777$ \\
\hline$R^{2}$ & 0.39 & & & 0.57 & & & $0 \cdot 42$ & & \\
\hline
\end{tabular}

Source: Own study.

The third hypothesis was tested for every component of a high-performance work system since these tests could disclose the understandings about in what way the different surfaces of HPWS impact the connection between burnout and EL. These tests provide the results that all the seven components of HPWS negatively moderate the association among EL and emotional exhaustion (EE).

\section{Discussion}

Perhaps this is the first HRM model that study simultaneously the impact of moderation of HPWS on the connection between EL and burnout together with the mediation impact of burnout over the connection between EL and ITL. The outcomes of this research propose that every single component of HPWS lessens the opposing impact of EL over burnout. In addition, though the EL is positively linked with ITL, the EL possesses an indirect impact over ITL by means of burnout. The results of the research highlight the significance of HPWS along with the recommendation that positive insight of high-performance work system might shock the impact of EL on burnout. This is a strong finding since the administration of the firm could influence HPWS. The human resource department is accountable for the components of HPWS that are transformational leadership, information sharing, selective hiring, training and development, job security, decentralized decision making, and teams. If the supervisors all around the organization specifically the nursing unit can confirm the suitable existence of HPWS in place, the harmful influence of EL can be minimalized.

The results of the study indicate the significance of HR practices that can lessen the negative impact of burnout and increase satisfaction along with long-lasting retention (Bartram et al., 2012). Burnout significantly mediates the connection between ITL and EL. This outcome of the study recommends that the job demands like EL give rise to the burnout and eventually the nurses and midwives generate a thought to leave the organization or switch from their career. This outcome is dependable on the JD-R theory. These outcomes are in-line with the previous 
literature that claims the negative impact of EL that leads to EE and ITL (GarcíaChas, Neira-Fontela, and Castro-Casal, 2014).

According to the results of the study, is can be observed that the HPWS not only reduces the negative impacts of EL on burnout but also responds to the burnout over ITL. Undoubtedly, the most constructive forecaster of ITL is HPWS. The ITL could be decreased by HPWS through practicing social exchange. Particularly, the workers of the organization can assume HPWS as a symbol that organization values their existence and their efforts (Heffernan and Dundon, 2016). Therefore, the workers will show even more loyalty to the firm irrespective of their jobs being demanding.

\section{Conclusion}

The new model of human resource management is established in this study to support and manage emotional labor in the presence of a high-performance work system that acts as a mediator. The HPWS is known as an effective HR strategy that has a tendency to lessen the impacts of emotional labor. The different components of a high-performance work system in the healthcare department of the organization include decentralized decision making, aggressive hiring, extensive training, teams, and transformational leadership. The factor of emotional labor is cantered to the emergency occupations such as army man, healthcare staff, fire-fighters, and contingency planners and rescue volunteers. Retaining the nurses and midwives whose jobs are demanding needs highly effective policies by human resource authorities so that retaining them could become easier and these workers will feel satisfied with their jobs.

Through HPWS, employees will feel valued by the organization and will agree to work under stressful situations in order to meet the organizational goals. HPWS also copes with the factor of burnout and it leads to lesser intention to leave. The organization must pay attention to strengthening HPWS for the betterment of workers as satisfied workers have a direct relationship with the productivity of the firm as well as its profitability.

\section{Recommendations}

Although this research has proposed the new model for human resource management practices regarding the emotional labor in the presence of high-performance work system as a mediator in a case study of a Jordian public hospital, the future scholars who look forward to presenting the future version of this model need to add more variables to the model and advance it for proposing even more strong model to the HRM of any organization concerning to their emergency workers. As far as, the human resource department and its practices are a concern, they need to improve their practices specifically for emergency workers such as nurses and midwives so that the degree of burnout and their intention to leave or either switching the profession could be decreased and they will be retained in the organization for a 
longer period. However, through improving the HR policies, the employees will feel more engaged and work harder to achieve organizational goals and work for their productivity through providing quality care.

This conceptual model will prove to be the effort made in the way of HRM policies and behavior regarding emotional labor throughout the emergency situation. This study will be useful for firms in designing their policies and strategies that support emotional labor in emergencies. Further, this study will also going to help future researchers who are looking forwards to conduct the study on the same issue. They can take this study to another level by adding more variables to the study and proposing its advanced model. In addition, this study will be effective for the students who are getting their higher degrees in the proposed research topic and will make them gain something from it in their future decision makings as being the senior HR professionals of the firm.

\section{Limitations of the Study}

As every work has some sort of limitations, the same goes for this research study as well. This study faces the issue of reaching to the target population of the study as this study was focused on the emotional labor of emergency workers. Secondly, getting the permission letter from the selected organization was another limitation that interrupts the study. In addition, the ongoing world situation of COVID-19 was among the biggest barriers to reach to the respondents as following the SOP's and handling the situation of lockdown was difficult and it also limits the time for the study. Handling the current situation and coping with all the barriers was the biggest problem to come up with the best solution to the study.

\section{References:}

Alrawadieh, Z., Cetin, G., Dincer, M.Z., Istanbullu Dincer, F. 2019. The impact of emotional dissonance on quality of work life and life satisfaction of tour guides. The Service Industries Journal, 40(1-2), 50-64. doi:10.1080/02642069.2019.1590554.

Andersén, J., Andersén, A. 2019. Are high-performance work systems (HPWS) appreciated by everyone? The role of management position and gender on the relationship between HPWS and affective commitment. Employee Relations: The International Journal, 41(5), 1046-1064. doi: 10.1108/ER-03-2018-0080.

Antoniou, C., Doukas, J.A., Subrahmanyam, A. 2013. Cognitive dissonance, sentiment, and momentum. Journal of Financial and Quantitative Analysis, 48(1), 245-275. doi: $10.2139 /$ ssrn. 1479197.

Bakker, A.B., Demerouti, E. 2014. Job demands-resources theory. Wellbeing: A complete reference guide, 1-28. John Wiley \& Sons, Ltd. doi: 10.1002/9781118539415.wbwell019.

Bakker, A.B., Demerouti, E., Sanz-Vergel, A.I. 2014. Burnout and work engagement: The JD-R approach. Annual Review of Organizational Psychology and Organizational Behavior, 1, 389-411. doi: 10.1146/annurev-orgpsych-031413091235. 
Bartram, T., Casimir, G., Djurkovic, N., Leggat, S.G., Stanton, P. 2012. Do perceived high performance work systems influence the relationship between emotional labor, burnout and intention to leave? A study of Australian nurses. Journal of Advanced Nursing, 68(7), 1567-1578. doi: 10.1111/j.1365-2648.2012.05968.x.

Biron, M., Van Veldhoven, M. 2012. Emotional labor in service work: Psychological flexibility and emotion regulation. Human Relations, 65(10), 1259-1282. doi: $10.1177 / 0018726712447832$.

Brunetto, Y., Shacklock, K., Teo, S., Farr-Wharton, R. 2014. The impact of management on the engagement and well-being of high emotional labor employees. The International Journal of Human Resource Management, 25(17), 23452363. doi:10.1080/09585192.2013.877056.

Cheng, C., Bartram, T., Karimi, L., Leggat, S.G. 2013. The role of team climate in the management of emotional labor: implications for nurse retention. Journal of advanced nursing, 69(12), 2812-2825. doi: 10.1111/jan.12202.

Delgado, C., Upton, D., Ranse, K., Furness, T., Foster, K. 2017. Nurses' resilience and the emotional labor of nursing work: An integrative review of empirical literature. International Journal of Nursing Studies, 70, 71-88. doi: 10.1016/j.ijnurstu.2017.02.008.

Freitas, A.R., Carneseca, E.C., Paiva, C.E., Paiva, B.S.R. 2014. Impact of a physical activity program on the anxiety, depression, occupational stress and burnout syndrome of nursing professionals. Revista latino-americana de enfermagem, 22(2), 332-336. doi: 10.1590/0104-1169.3307.2420.

García-Chas, R., Neira-Fontela, E., Castro-Casal, C. 2014. High-performance work system and intention to leave: a mediation model. The International Journal of Human Resource Management, 25(3), 367-389. doi: 10.1080/09585192.2013.789441.

García-Chas, R., Neira-Fontela, E., Castro-Casal, C. 2013. High-performance work system and intention to leave: a mediation model. The International Journal of Human Resource Management, 25(3), 367389. doi:10.1080/09585192.2013.789441.

Geng, Z., Li, C., Bi, K., Zheng, H., Yang, X. 2018. Motivating service employee creativity: regulatory focus and emotional labor. Journal of Service Theory and Practice, 28(2), 228-249. doi:10.1108/jstp-11-2016-0214.

Heffernan, M., Dundon, T. 2016. Cross-level effects of high-performance work systems (HPWS) and employee well-being: the mediating effect of organisational justice. Human Resource Management Journal, 26(2), 211-231. doi: 10.1111/17488583.12095.

Huang, L.C., Ahlstrom, D., Lee, A.Y.P., Chen, S.Y., Hsieh, M.J. 2016. High performance work systems, employee well-being, and job involvement: An empirical study. Personnel Review, 45(2), 296-314. doi: 10.1108/PR-09-2014-0201.

Jensen, J.M., Patel, P.C., Messersmith, J.G. 2013. High-performance work systems and job control: Consequences for anxiety, role overload, and turnover intentions. Journal of Management, 39(6), 1699-1724. doi: $10.1177 / 0149206311419663$.

Jeung, D.Y., Kim, C., Chang, S.J. 2018. Emotional labor and burnout: a review of the literature. Yonsei medical journal, 59(2), 187-193. doi: 10.3934/publichealth.2019.3.268.

Karimi, L., Cheng, C., Bartram, T., Leggat, S.G., Sarkeshik, S. 2014. The effects of 
emotional intelligence and stress-related presenteeism on nurses' well-being. Asia Pacific Journal of Human Resources, 53(3), 296-310. doi:10.1111/17447941.12049.

Karimi, L., Leggat, S.G., Donohue, L., Farrell, G., Couper, G.E. 2014. Emotional rescue: The role of emotional intelligence and emotional labor on well-being and job-stress among community nurses. Journal of advanced nursing, 70(1), 176-186. doi: 10.1111/jan.12185.

Kloutsiniotis, P.V., Mihail, D.M. 2019. Is it worth it? Linking perceived highperformance work systems and emotional exhaustion: The mediating role of job demands and job resources. European Management Journal, 38(4), 565-579. doi:10.1016/j.emj.2019.12.012.

Kloutsiniotis, P.V. and Mihail, D.M., 2017. Linking innovative human resource practices, employee attitudes and intention to leave in healthcare services. Employee Relations, 39(1), 34-53 doi: 10.1108/ER-11-2015-0205.

Kroon, B., van de Voorde, K., van Veldhoven, M., 2009. Cross-level effects of high-performance work practices on burnout. Personnel Review, 38(5), 509525. doi:10.1108/00483480910978027.

Lartey, J.K.S., Amponsah-Tawiah, K., Osafo, J. 2019. The moderating effect of perceived organizational support in the relationship between emotional labor and job attitudes: A study among health professionals. Nursing Open, 6(3), 990-997. doi: 10.1002/nop2.295.

Nantsupawat, A., Kunaviktikul, W., Nantsupawat, R., Wichaikhum, O.A., Thienthong, H., Poghosyan, L. 2017. Effects of nurse work environment on job dissatisfaction, burnout, and intention to leave. International nursing review, 64(1), 91-98.

O’Brien, E., Linehan, C. 2016. The last taboo? surfacing and supporting Emotional Labor in HR work. The International Journal of Human Resource Management, 29(4), 683-709. doi:10.1080/09585192.2016.1184178.

Pandey, J. 2018. Managing emotional labor for service employees: an HRM-based approach. Human Resource Management International Digest, 26(4), 1 4. doi:10.1108/hrmid-04-2017-0072.

Ravitch, S.M., Riggan, M. 2016. Reason \& rigor: How conceptual frameworks guide research. Sage Publications. doi: 10.7748/nr.2020.e1683.

Santos, A., Mustafa, M.J., Gwi, T.C. 2015. Trait emotional intelligence, emotional labor, and burnout among Malaysian HR professionals. Management Research Review, 38(1), 67-88. doi: 10.1108/MRR-06-2013-0143.

Smith, K.B., Profetto-McGrath, J., Cummings, G.G. 2009. Emotional Intelligence and Nursing: An Integrative Literature Review. International Journal of Nursing Studies, 46, 1624-1636. doi: 10.1016/j.jinurstu.2009.05.024.

Tofighi, M., Tirgari, B., Fooladvandi, M., Rasouli, F., Jalali, M. 2015. Relationship between emotional intelligence and organizational citizenship behavior in critical and emergency nurses in South East of Iran. Ethiopian journal of health sciences, 25(1), 79-88. doi: 0.4314/ejhs.v25i1.11.

Van Bogaert, P., Timmermans, O., Weeks, S.M., van Heusden, D., Wouters, K., Franck, E. 2014. Nursing unit teams matter: Impact of unit-level nurse practice environment, nurse work characteristics, and burnout on nurse reported job outcomes, and quality of care, and patient adverse events: A cross-sectional survey. International journal of nursing studies, 51(8), 1123-1134. doi: /10.1016/j.ijnurstu.2013.12.009.

Van der Togt, J., Rasmussen, T.H. 2017. Toward evidence-based HR. Journal of Organizational Effectiveness: People and Performance, 4(2), 127-132. doi: 
10.1108/JOEPP-02-2017-0013.

Wu, X., Shie, A.J. 2017. The relationship between customer orientation, emotional labor and job burnout. Journal of Chinese Human Resources Management, 8(2), 5476. doi:10.1108/jchrm-03-2017-0005.

Zhao, X.R., Qu, H., Ghiselli, R. 2011. Examining the relationship of work-family conflict to job and life satisfaction: A case of hotel sales managers. International Journal of Hospitality Management, 30(1), 46-54. doi: 10.1016/j.ijhm.2010.04.010.

\section{Appendix:}

\section{Survey questionnaire:}

\begin{tabular}{|c|c|c|c|c|c|c|}
\hline S.No & Items & S.A & $\mathbf{A}$ & $\mathbf{N}$ & D & S.D \\
\hline & Emotional labor & & & & & \\
\hline 1 & $\begin{array}{l}\text { I just made-up to have the sentiments that I am required to } \\
\text { show for my job }\end{array}$ & & & & & \\
\hline 2 & $\begin{array}{l}\text { I attempt to truly experience the emotions that I necessarily } \\
\text { needs to show to customers }\end{array}$ & & & & & \\
\hline 3 & $\begin{array}{l}\text { to please the customers, I will make an effort to understand } \\
\text { their emotional state }\end{array}$ & & & & & \\
\hline 4 & The feelings that I express to customers are honest & & & & & \\
\hline \multirow[t]{2}{*}{5} & The emotions that I display to customers come out naturally & & & & & \\
\hline & HPWS & & & & & \\
\hline 1 & $\begin{array}{l}\text { Candidates for this job experience structured interviews } \\
\text { before being hired }\end{array}$ & & & & & \\
\hline 2 & $\begin{array}{l}\text { The nurses in this job have the chance to earn group bonuses } \\
\text { for efficiency, performance, or other group performance } \\
\text { results }\end{array}$ & & & & & \\
\hline 3 & $\begin{array}{l}\text { Minimum of once a year nurses in this job accept a formal } \\
\text { assessment of their job }\end{array}$ & & & & & \\
\hline 4 & $\begin{array}{l}\text { Nursing staff in this job frequently receive formal } \\
\text { communication concerning the company objectives and } \\
\text { aims }\end{array}$ & & & & & \\
\hline \multirow[t]{2}{*}{5} & The firm employs only the very best people for this .job & & & & & \\
\hline & Burnout & & & & & \\
\hline 1 & Do u ever Feel emotionally drained from my work? & & & & & \\
\hline 2 & $\begin{array}{l}\text { I feel fatigued when I get up in the morning and have to face } \\
\text { another day on the job. }\end{array}$ & & & & & \\
\hline 3 & I can easily understand how my patients feel about things. & & & & & \\
\hline 4 & I worry that this job is hardening me emotionally. & & & & & \\
\hline \multirow[t]{2}{*}{5} & Working with people directly puts too much stress on me. & & & & & \\
\hline & Intention to leave & & & & & \\
\hline 1 & $\begin{array}{l}\text { In the last few months, I have seriously thought about } \\
\text { looking for a new job }\end{array}$ & & & & & \\
\hline 2 & I plan to stay in my hospital as long as possible & & & & & \\
\hline 3 & I am actively searching for new jobs these days? & & & & & \\
\hline 4 & Will probably look for a new job in the next year. & & & & & \\
\hline 5 & I often think of changing my field of work & & & & & \\
\hline
\end{tabular}

